\title{
Research
}

\section{Screening for sickle cell and thalassaemia in primary care:}

\author{
a cost-effectiveness study
}

\begin{abstract}
Background

Haemoglobinopathies, including sickle cell disease and thalassaemia (SCT), are inherited disorders of haemoglobin. Antenatal screening for SCT rarely occurs before 10 weeks of pregnancy.
\end{abstract}

\section{Aim}

To explore the cost-effectiveness of offering SC screening in a primary care setting, during the pregnancy confirmation visit.

\section{Design and setting}

A model-based cost-effectiveness analysis of inner-city areas with a high proportion of residents from ethnic minority groups.

\section{Method}

Comparison was made of three SCT screening approaches: 'primary care parallel' (primary care screening with test offered to mother and father together): 'primary care sequential' (primary care screening with test offered to the mother and then the father only if the mother is a carrier); and 'midwife care' (sequential screening at the first midwife consultation). The model was populated with data from the SHIFT (Screening for Haemoglobinopathies In First

Trimester) trial and other sources.

\section{Results}

Compared to midwife care, primary care sequential had a higher NHS cost of $€ 34000$ per 10000 pregnancies $195 \%$ confidence interval $[\mathrm{Cl}]=£ 15000$ to $€ 51000$ ) and an increase of 2623 women screened $195 \% \mathrm{Cl}$ : 1359 to 4495), giving a cost per additional woman screened by 10 weeks of $€ 13$. Primary care parallel was dominated by primary care sequential, with both higher costs and fewer women screened.

\section{Conclusion}

The policy judgement is whether an earlier opportunity for informed reproductive choice has a value of at least $€ 13$. Further work is required to understand the value attached to earlier informed reproductive choices.

\section{Keywords}

antenatal diagnosis; cost effectiveness; hemoglobin $\mathrm{S}$ disease; primary care thalassemia.

\section{INTRODUCTION}

Haemoglobinopathies, including sickle cell disease and thalassaemia (SCT), are inherited disorders of haemoglobin. In England, the NHS Sickle Cell and Thalassaemia Screening Programme offers screening, typically in the first midwife consultation, to facilitate informed decision making by prospective parents. The programme aims for screening to be offered by 10 weeks' gestation, so that the screening process might be completed by 12 weeks. This allows couples the opportunity to consider their reproductive choices, including prenatal diagnosis and termination, early in pregnancy. There is, of course, no guarantee that earlier screening will lead to more women choosing prenatal tests or terminations, but it is known that many at-risk pregnant women, and fathers of their babies, are offered SCT screening too late in pregnancy to allow any reproductive choice. "The SHIFT (Screening for Haemoglobinopathies In the First Trimester] trial was a response to this concern and sought to assess the effectiveness, costeffectiveness, feasibility, and acceptability of offering universal antenatal SCT screening in primary care when the pregnancy is first confirmed. Three alternative approaches to SCT screening were compared:

- 'primary care parallel' - screening in

S Bryan, PhD, professor, Health Economics Unit, University of Birmingham and Professor, School of Population and Public Health, University of British Columbia, Vancouver, Canada. E Dormandy, PhD, trial manager; TM Marteau, PhD, professor, Psychology Department (at Guy's), King's College, London. TE Roberts, PhD, professor; P Barton, PhD, reader; A Juarez-Garcia $P h D$, research fellow: $L$ Andronis, MSc, research fellow, Health Economics Unit, University of Birmingham, Birmingham. AE Ades, PhD, professor, Primary Health Care, University of Bristol, Bristol. J Karnon, PhD, professor, School of Population Health and Clinical Practice. University of Adelaide, Australia. primary care with the test offered to the mother and father at the same time;

- 'primary care sequential' - screening in primary care with the test offered to the mother and then subsequently to the father only if the mother is a carrier; or

- 'midwife care' - sequential screening at the first midwife consultation.

The study involved a cluster randomised trial undertaken in two inner-city London boroughs with a high proportion of residents from ethnic minority groups. The main finding was that offering SCT screening in primary care was effective (that is, the proportion of women screened before 10 weeks' gestation) but still only a minority of women were screened before 10 weeks. ${ }^{2,3}$ The trial was supplemented with a modelbased cost-effectiveness analysis that sought to estimate the additional costs associated with primary care screening, both sequential and parallel, and the benefits in terms of the number of additional women screened before 10 weeks gestation. This paper reports the costeffectiveness component of the SHIFT trial. ${ }^{2}$

\section{METHOD}

Overview

The cluster randomised SHIFT trial included all pregnant women from 27

\section{Address for correspondence}

Stirling Bryan, School of Population and Public Health, University of British Columbia, 702-828 West 10th Avenue, Vancouver, BC V5Z 1M9, Canada.

E-mail: stirling.bryandubc.ca

Submitted: 23 December 2010; Editor's response: 27 January 2011; final acceptance: 28 February 2011.

\section{()British Journal of General Practice}

This is the full-length article (published online 26 Sep 2011) of an abridged version published in print. Cite this article as: Br J Gen Pract 2011; DOI: 10.3399/bjgp11X601325. 


\section{How this fits in}

In England, screening for sickle cell and thalassaemia (SCT) typically happens in the first midwife consultation. The aim is for screening to be offered by 10 weeks gestation, but it is known that many at-risk pregnant women are offered screening too late to allow any reproductive choice. This research was a response to this concern and assessed the cost-effectiveness of universal antenatal SCT screening in a primary care setting, during the pregnancy confirmation visit. The study indicates a price of approximately $€ 13$ for each additional woman screened by 10 weeks.

general practices across two primary care trusts in two London boroughs. Practices were allocated to one of the three screening policies ('primary care parallel', 'primary care sequential', and 'midwife care'), and the primary outcome was the proportion of women screened before 10 weeks gestation. Full details of the trial design and results are reported elsewhere., ${ }^{2,3}$ The economic analysis in SHIFT sought to predict the costs and benefits associated with the three strategies, in populations similar to those observed in the trial. An incremental analysis was adopted, the increment being the difference in costs and benefits between trial arms, with "midwife care' as the default comparator.

\section{The economic model}

The SHIFT modelling work used an existing published model, reported by Zeuner et al, ${ }^{4}$ as a starting point. The model structure is based on the chronological sequence of steps during the screening process, as described in Figure 1. The time horizon modelled covered pregnancies to their conclusion (that is, birth, termination, or other pregnancy loss unrelated to screeningl but did not include the effects of screening on future pregnancies.

A universal screening strategy, as observed in the trial, was modelled such that all women (with the exception of those who present after 20 weeks' gestation) are eligible for screening. Not all women in the trial underwent screening, and so the proportion of all eligible women screened is a model parameter. Some of the key model assumptions are: (1) where a woman is identified as a carrier and the father is not available for testing, the woman is offered prenatal diagnosis (PND); (2) the declared partner is not necessarily the biological father; (3) a woman presenting after the end of the second trimester (20 weeks' gestation) is too late to receive screening; (4) spontaneous miscarriage of a pregnancy can occur; (5) test results for women and their partners can be falsenegative or false-positive; (6) the acceptance rates for PND and termination of pregnancy (TOP) may be time dependent, with earlier screening associated with higher rates; and (7) PND can induce miscarriage.

\section{Cost data}

The screening programme costs are categorised as: screening and testing, counselling, PND, and TOP. The healthsector perspective was adopted as the base case, considering costs to the NHS only, but this was broadened to also include serviceuser costs as a sensitivity analysis. Resource-use data were collected on shortterm events such as screening offer counselling lof the carrier woman, father or couple), diagnostic testing, and subsequent procedures. These data were extracted from routine medical records of trial participants. Data on the additional time associated with primary care screening and the personnel involved were gathered from computerised practice records and interviews with the personnel involved. The unit costs associated with laboratory tests were accessed from laboratory pricing schedules. Information on other unit costs or prices (for example, relating to PND and TOP) were collected from relevant routine sources and hospital finance departments, so that an overall cost per screened woman could be calculated. ${ }^{5,6}$ All costs are reported in 2010 prices, inflated using Hospital and Community Health Services (HCHS) inflation indices. ${ }^{7}$ No discounting was necessary, given the short-term horizon of the clinical events.

A sample of women and their partners across all trial arms were asked to complete a patient cost questionnaire, to record the private costs of undergoing screening (for example, travel costs, time off work, lost income and childcare costs). Private costs for post-testing procedures such as PND and TOP were based on data from interviews with service personnel.

\section{Other model parameters}

Table 1 reports the model parameters describing the antenatal population studied and the screening pathways modelled. All parameters in the original Zeuner model ${ }^{4}$ were reviewed, and a judgement made concerning updating. Data from the SHIFT 


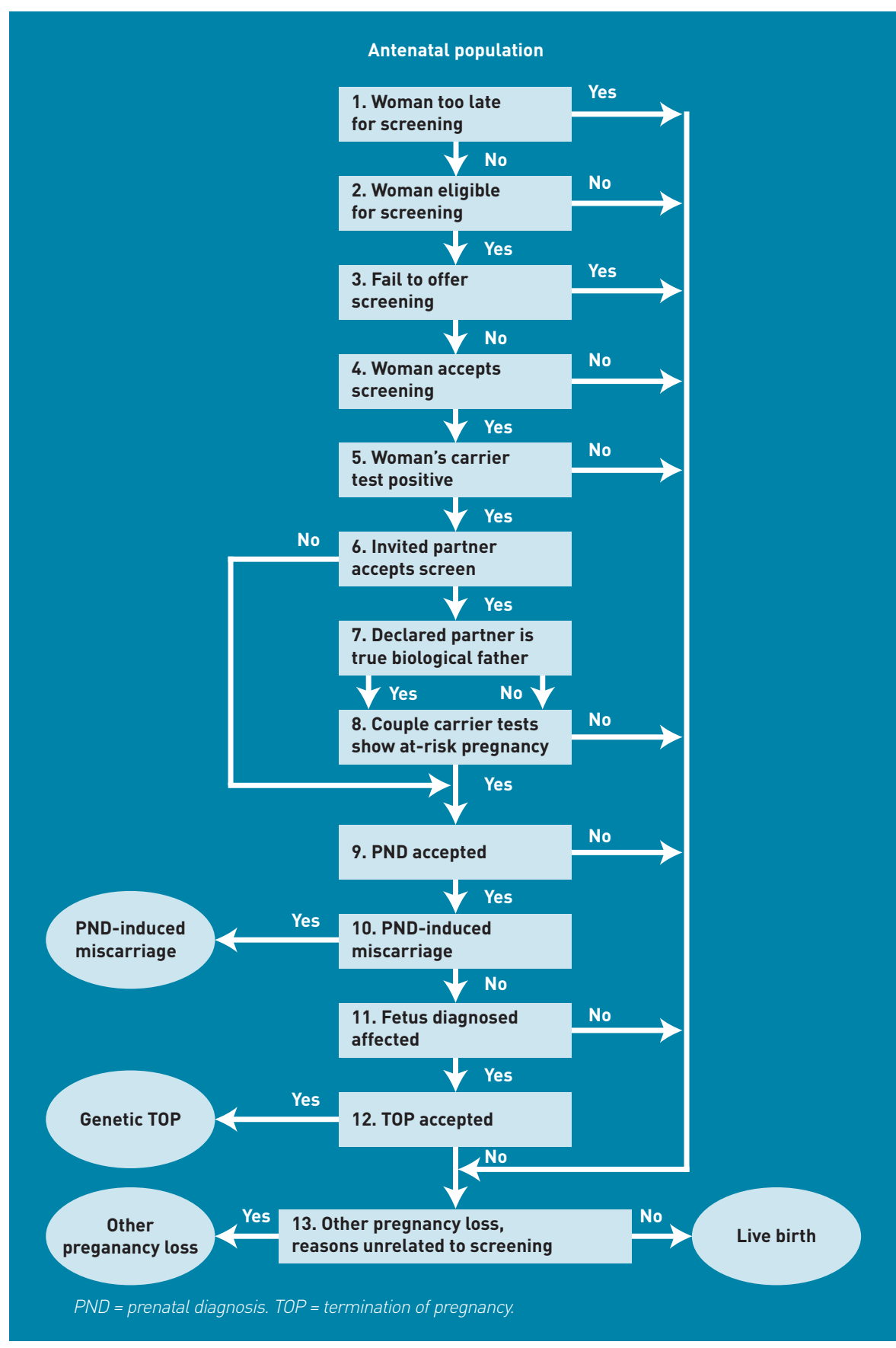

Figure 1. Screening flow diagram. trial were used, where available, and other parameter values updated where new data could be accessed from published sources. Estimates of the proportion of women screened by trial arm and gestational age were modelled using Bayesian Markov Chain Monte Carlo (MCMC) methods implemented in WinBUGS 1.4.3.8 MCMC has a simulation format compatible with probabilistic cost-effectiveness analysis, but also can readily take clustering, as seen in the SHIFT trial, into account.? Further details of this MCMC analysis are given in Dormandy et al. ${ }^{2}$

\section{Base case and sensitivity analysis}

A base case analysis, from a health-sector perspective, is first presented, representing the population of women seen in the trial and using the parameter values as defined in Table 1. The probabilistic analysis focused on parameters populated by new SHIFT trial data, with the following parameters varied: ethnic mix of the screened population (sampling from a Dirichlet distribution), proportion of women not screened (sampling from a beta distribution), probability that the father is tested when the woman is a carrier (sampling from a beta distribution), and proportions of women screened by $6,10,14$, 18 , and 22 weeks (based on iterations from the MCMC analysis). The probabilistic analyses were based on 7000 replications of the model. The base case costeffectiveness results represent mean values from the probabilistic analyses, reported with $95 \%$ confidence intervals (Cls), which represent the range (from 2.5\% to $97.5 \%$ ) of the distribution of outputs from the probabilistic model runs.

As a sensitivity analysis, the perspective was broadened to include costs falling on service users, using private cost data collected within the trial.

\section{RESULTS}

\section{Base case analysis}

The SHIFT trial found a significantly higher proportion of women screened by 10 weeks in primary care lthat is, 0.28 in primary care sequential compared to 0.02 in midwife care). Table 2 reports the unit cost estimates used in the economic analysis. The estimated additional length of the primary care consultation, as a result of introducing the screening test was estimated to be 3 minutes, with a further 0.5 minutes if the father was present. This estimate was based on interview data.

The base case results from the probabilistic analyses are reported in Table 3 , where, for convenience and ease of interpretation, all figures are expressed as a rate per 10000 pregnancies. Screening in primary care is associated with a higher NHS cost of between $£ 34000$ and $£ 57000$ per 10000 pregnancies, depending on the screening approach considered compared to midwife care. However, this higher expenditure is mirrored by greater effectiveness, measured by the number of women screened by 10 weeks' gestation. The predictions from the model for process measures and outcomes not collected in the trial, such as PND rates, TOP rates, and affected births, are also reported in Table 3 , 


\begin{tabular}{|c|c|c|}
\hline Parameter & Value/calculation & Source \\
\hline $\begin{array}{l}\text { Ethnic composition of the } \\
\text { antenatal population }\end{array}$ & $\begin{array}{l}\text { North European = 298/1454 } \\
\text { South or South East Asian = 420/1454 } \\
\text { African/Caribbean }=357 / 1454 \\
\text { South European }=280 / 1454 \\
\text { Other }=61 / 1454 \\
\text { Mixed }=38 / 1454\end{array}$ & Dormandy et al, 2010² \\
\hline $\begin{array}{l}\text { Inter-ethnic unions } \\
2003^{10}\end{array}$ & $P=0.0373$ & Office for National Statistics, \\
\hline $\begin{array}{l}\text { Mendelian recessive } \\
\text { inheritance }\end{array}$ & $\begin{array}{l}\text { If both parents are carriers: } \\
P=0.25 \text { (child inherits both traits) } \\
P=0.50 \text { (child inherits one trait) } \\
P=0.25 \text { (child inherits no trait) } \\
\text { If one parent is a carrier: } \\
P=0.50 \text { (child inherits one trait) } \\
P=0.50 \text { (child inherits no trait) }\end{array}$ & Zeuner et al, $1999^{4}$ \\
\hline $\begin{array}{l}\text { Declared father's } \\
\text { paternity }\end{array}$ & $\begin{array}{l}\text { Declared father is not the } \\
\text { biological father, } P=0.037\end{array}$ & Bellis et al, 2005'11 \\
\hline $\begin{array}{l}\text { Failure to screen } \\
\text { eligible women }\end{array}$ & $\begin{array}{l}\text { Midwife }=117 / 441 \\
\text { Primary care parallel }=106 / 677 \\
\text { Primary care sequential = 109/590 }\end{array}$ & Dormandy et al, 2010² \\
\hline $\begin{array}{l}\text { Declared father } \\
\text { accepts screening }\end{array}$ & $\begin{array}{l}\text { Father is tested when maternal } \\
\text { result is positive: Midwife }=10 / 20 \\
\text { Primary care parallel }=20 / 47 \\
\text { Primary care sequential }=14 / 24 \\
\text { Father is tested when maternal } \\
\text { result is negative: Primary care parallel } \\
=32 / 524\end{array}$ & Dormandy et al, $2010^{2}$ \\
\hline Woman accepts PND & As in Zeuner et al, $1999^{4}$ & Zeuner et al, $1999^{4}$ \\
\hline PND-induced miscarriage & $P=0.015$ & Zeuner et al, $1999^{4}$ \\
\hline Woman accepts TOP & $\begin{array}{l}\text { Thalassaemia: } P=0.95 \\
\text { Sickle cell disease: } P=0.70\end{array}$ & Zeuner et al, $1999^{4}$ \\
\hline $\begin{array}{l}\text { Failure of fetus to } \\
\text { reach term }\end{array}$ & $P=0.14$ & Slattery and Morrison, $2002^{12}$ \\
\hline
\end{tabular}

with a result of similar outcomes predicted for all three trial arms.

The results for effectiveness are put alongside the cost results in Table 4, with results reported as incremental costeffectiveness ratios (ICERs), comparing both primary care strategies to the sequential midwife care model. The results indicate a cost-effectiveness ratio of $€ 13$ per additional woman screened by 10 weeks, for the move away from the midwife care service to a primary care sequential programme. Given the very small and uncertain differences between strategies in terms of other outcome measures (for example, PND, TOP, and affected births), further ICERs (for example, cost per affected birth avoided) are not reported.

The more costly primary care option is parallel testing but this appears not to be

Table 2. Model cost inputs

\begin{tabular}{|c|c|c|c|}
\hline Cost variable & NHS cost & Private cost & Source \\
\hline \multirow[t]{3}{*}{ Carrier test (woman) } & Midwife $=€ 8.80$ & $€ 11.47$ & Dormandy et al, 2010²; Curtis and Netten, $2006^{6}$ \\
\hline & Primary care parallel $=€ 13.51$ & & \\
\hline & Primary care sequential $=€ 12.30$ & & \\
\hline \multirow[t]{3}{*}{ Carrier test (father) } & Midwife $=€ 5.74$ & $€ 11.47$ & Dormandy et al, 2010²; Curtis and Netten, $2006^{6}$ \\
\hline & Primary care parallel $=€ 6.09$ & & \\
\hline & Primary care sequential $=€ 5.74$ & & \\
\hline Carrier status counselling (woman only) & $£ 16.13$ & €6.18 & Roberts et al, 2007'13; Curtis and Netten, $2006^{6}$ \\
\hline Carrier status counselling (couple) & $€ 47.63$ & $€ 10.27$ & Roberts et al, $2007^{13} ;$ Curtis and Netten, $2006^{6}$ \\
\hline$\overline{P N D}$ & $€ 343.23$ & $€ 67.18$ & Bricker et al, $2000^{14}$; Department of Health, $2006^{5}$ \\
\hline TOP counselling & $€ 47.25$ & $€ 10.27$ & Curtis and Netten, $2006^{6}$ \\
\hline TOP procedure & $€ 489.00$ & $€ 67.18$ & Department of Health, $2006^{5}$ \\
\hline
\end{tabular}

$P N D=$ prenatal diagnosis. TOP = termination of pregnancy. Private costs refer to additional costs incurred by patients. 
Table 3. Base case results: model predictions per 10000 pregnancies, point estimates and $95 \%$ Cls

\begin{tabular}{|c|c|c|c|}
\hline & Midwife care & Primary care parallel & Primary care sequential \\
\hline Health-sector costs & $£ 145000$ ( $€ 119000$ to $€ 167000$ ) & $£ 201000$ ( $€ 169000$ to $€ 225000$ ) & $£ 178000$ ( $€ 149000$ to $€ 203000)$ \\
\hline Women screened by 70 days & 264 (92 to 580$)$ & 2556 (1276 to 4444$)$ & 2887 (1509 to 4930) \\
\hline PND procedures & 50 (40 to 61$)$ & $57(48$ to 66$)$ & 50 (41 to 60 ) \\
\hline TOP procedures & 3.82 (2.94 to 4.68$)$ & 3.88 (3.17 to 4.61$)$ & 4.56 (3.63 to 5.53 ) \\
\hline Affected births & 27.83 (25.77 to 30.00$)$ & 27.83 (25.79 to 29.96$)$ & 27.17 (25.07 to 29.38$)$ \\
\hline
\end{tabular}

Table 4. Incremental cost-effectiveness ratios (ICERs)

\begin{tabular}{|c|c|c|c|}
\hline & Increase in cost ${ }^{a}$ & $\begin{array}{c}\text { Increase in number of } \\
\text { women screened by } 70 \text { days }\end{array}$ & $\begin{array}{l}\text { ICER (woman } \\
\text { screened by } 70 \text { days) }\end{array}$ \\
\hline \multicolumn{4}{|l|}{ Base case results } \\
\hline Primary care sequential versus midwife care & $£ 33000$ & 2623 & $€ 13$ \\
\hline Primary care parallel versus midwife care & $€ 56000$ & 2292 & $€ 25$ \\
\hline Primary care parallel versus primary care sequential & $€ 23000$ & -331 & D \\
\hline \multicolumn{4}{|c|}{ Results from sensitivity analysis, including both NHS and private costs } \\
\hline Primary care sequential versus midwife care & $€ 40000$ & 2623 & $€ 15$ \\
\hline Primary care parallel versus midwife care & $€ 71000$ & 2292 & €32 \\
\hline Primary care parallel versus primary care sequential & $€ 32000$ & -331 & D \\
\hline
\end{tabular}

associated with more women being screened by 10 weeks, and so this option, at least in terms of the short-term screening ICER (that is, cost per woman screened), appears inferior to sequential screening in primary care.

The base case results from the probabilistic analyses are also reported using cost-effectiveness planes, given as Figures 2 and 3. A total of 7000 points is plotted on each scatter, representing the mean incremental cost and effectiveness estimates from each model run. The scatters are both entirely within the northeast quadrant of the plane, indicating that the primary care policy is associated with both a higher cost and a larger number of women screened. The central points in the scatters indicate incremental costs of $£ 57000$ (primary care parallel versus midwife care) and £34000 (primary care sequential versus midwife care) per 10000 women screened, in line with the cost figures reported in Table 4.

\section{Sensitivity analysis}

When the perspective was broadened to include private out-of-pocket costs, there was, as expected, no effect on the screening outcomes but it did increase the cost figures considerably (by approximately 60\%). The inclusion of private costs increased the cost for the midwife sequential strategy to approximately $€ 250000$ (for a screening population of 10000 women), and the revised costs for primary care parallel and primary care sequential respectively were approximately £322 000 and £290 000. The incremental analysis for this sensitivity analysis is reported in Table 4. Given that the incremental costs are higher than in the base case, the main ICER (comparing primary care sequential to midwife care) increased to $€ 15$ per additional woman screened by 70 days.

\section{DISCUSSION}

\section{Summary}

The cost-effectiveness analysis results indicate that the NHS would have to pay, on average, an additional $£ 13$ to achieve one additional pregnant woman screened by the 10-week threshold, using the sequential primary care screening model. On the basis of mean cost and effect estimates, the parallel primary care screening model is dominated by sequential screening, with both higher costs and lower screening rates.

\section{Strengths and limitations}

SHIFT made use of an existing model, developed over several years, reflecting the complexity of the clinical context and the screening pathways. Thus, modelling some of the detail of the clinical condition was already in place and so the focus was adaptation rather than modelling from scratch. Further, as part of this project, the model went through an extensive validation process with comparison made of model predictions and observed screening outcomes. One of the main data inputs for 
Figure 2. Cost-effectiveness plane - primary care parallel versus midwife care.

Figure 3. Cost-effectiveness plane - primary care sequential versus midwife care.
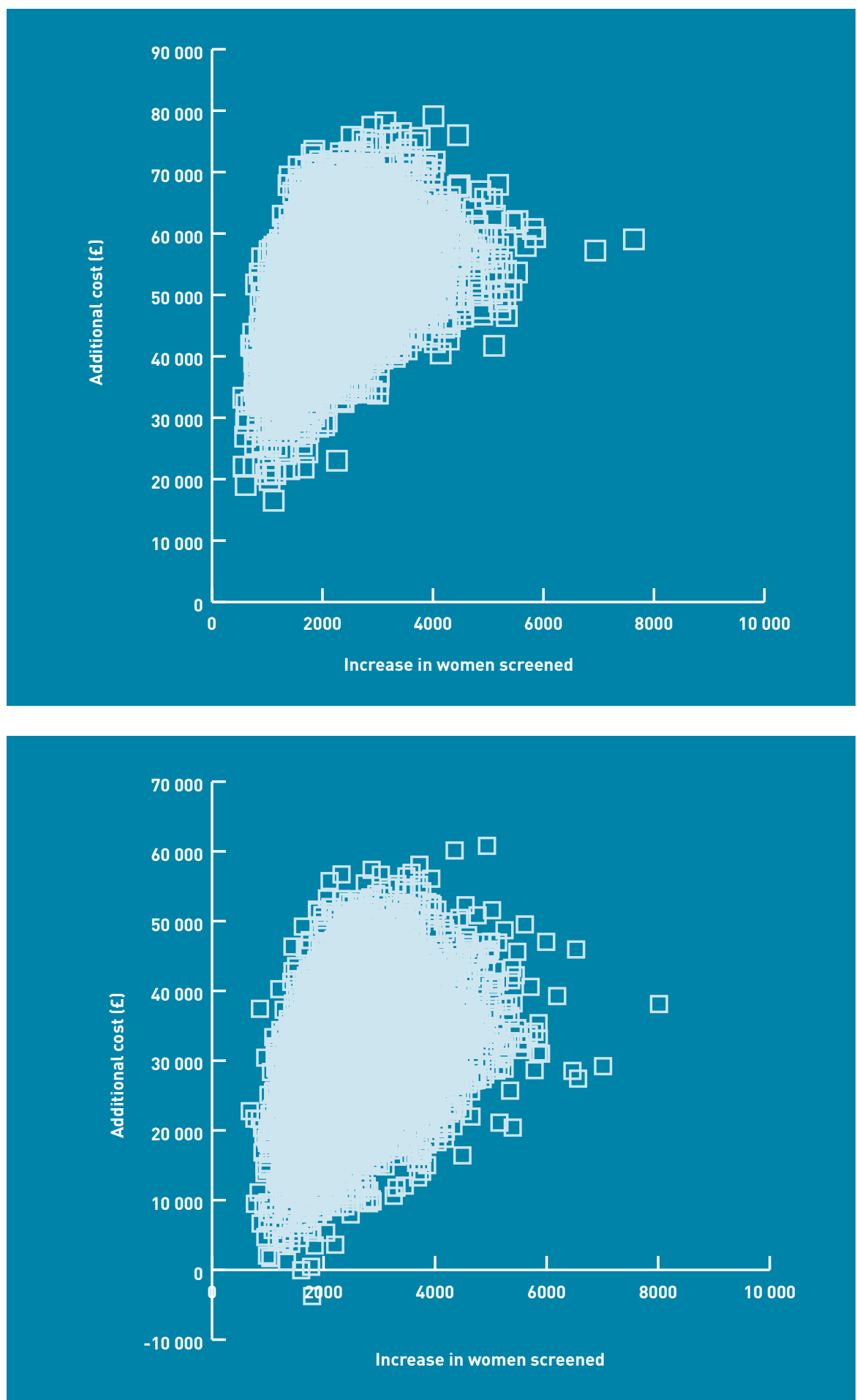

the model is the time to screen. An important strength of the work is that new data on this parameter were available from a large randomised controlled trial. Further these model inputs have been analysed, such that they adjust both for the cluster nature of the trial and for covariates (parity, age, and ethnicityl, using the WinBUGS based analyses of the time to screen data.

An important caveat relating to the cost- effectiveness results, however, concerns the paucity of data on the additional costs associated with the screening process. The predicted cost increase associated with primary care screening is driven largely by the increased duration of the general practice visit, a parameter about which limited data are available, because of the practical difficulty in gathering such information. However, it is important to 
recognise from a policy perspective that if primary care screening can be accommodated within the existing standard consultation, then its cost-effectiveness would look even more attractive. In addition, the incremental time cost associated with screening is likely to vary with the level of education and knowledge of the clinical issues among the prospective parents.

Training sessions were offered to practices that participated in the SHIFT study, but the costs associated with this training were not included in the costeffectiveness analysis for two reasons: (1) part of the training related to the research project (that is, information on the study protocol) and so would not be replicated in routine delivery of care; and (2) the clinical training costs were deemed to be negligible. The training was designed to be a brief oneoff session, and so when the training cost is distributed across all pregnancy confirmation visits over several years, the unit cost is trivial.

The sensitivity analysis reported here focused on the cost perspective to include private costs. Other sensitivity analyses were considered, particularly the ethnic mix question: how does the cost-effectiveness result change with variation in ethnic mix of the population? This question is not one the present study was able to address, given that the research was not undertaken across populations of different ethnic-mix compositions. For this reason, the researchers decided against sensitivity analyses that would give only speculative predictions relating to ethnic variations.

\section{Comparison with existing literature}

There is no extensive literature on the costeffectiveness of antenatal SCT carrier screening. The review presented in Karnon et al15 identified two small empirical studies that focus just on cost issues, ${ }^{16,17}$ and a model-based analysis. ${ }^{18}$ However, none of these studies explicitly addressed the question of the cost-effectiveness of screening in a primary care setting.

\section{Implications for practice and research}

This research suggests that an additional €13 would be required to achieve one additional pregnant woman screened by 10 weeks, using the sequential primary care screening model. The policy judgement is whether the benefits, in the form of providing women and couples with the opportunity to make informed reproductive choices have a value of greater than $€ 13$. If they do, then the results lend support for a policy of primary care sequential screening in inner-city populations similar to those observed in the trial, where universal screening is being offered.

In order to fully inform the policy judgement, further work is required to understand the value women and couples attach to informed reproductive choices early in pregnancy. The modelling work, where possible, based its inputs on new published evidence for model parameters. The project, therefore, serves to reemphasise the realities of important gaps in knowledge relating to this clinical area. For example, data on uptake of PND and TOP in this context are very sparse, particularly when issues of variation by ethnic group and timing of screening are considered. Research to investigate these aspects of the screening process is now required.

Finally, questions of generalisability need to be explored. The SHIFT trial was conducted in two UK primary care trusts ranked among the most deprived in England, with about $40 \%$ of their populations classified as representing ethnic minority groups. Further, the study areas were known to have a high prevalence of SCT - an estimated $6 \%$ of pregnant women in the study areas carry a significant haemoglobin variant. Clearly, this raises questions about the generalisability of the findings to other areas with lower prevalence. Given that the trial data relate only to high-prevalence areas, it is not possible to indicate the precise magnitude of variation in cost-effectiveness as the prevalence varies. However, it is clear that the cost-effectiveness will look less attractive in lower-prevalence areas. Further, the extent to which the study results can be applied in other contexts will also depend on the organisation of primary care services.

Davis, Barbara Wild, Moira Dick, Mike Calnan, Karl Atkin, Jane Logan, Fred Kavalier, Hilary Harris, Tracey Johnston, Elizabeth Anionwu, Vicki Tsianakas, Patricia Jones, and Susan Jowett.

\section{Discuss this article}

Contribute and read comments about this article on the Discussion Forum:

\section{http://www.rcgp.org.uk/bjgp-discuss}




\section{REFERENCES}

1. Dormandy E, Gulliford MC, Reid EP, et al. Delay between pregnancy confirmation and sickle cell thalassaemia screening: a population-based cohort study. Br J Gen Pract 2008; 58(548): 154-159

2. Dormandy E, Bryan S, Gulliford M, et al. Antenatal screening for haemoglobinopathies in primary care: a cohort study and cluster randomised trial to inform a simulation model. The Screening for Haemoglobinopathies in First Trimester (SHIFT) trial. Health Technol Assess 2010; 14(20): 1-160.

3. Dormandy E, Gulliford M, Bryan S, et al. Effectiveness of earlier antenatal screening for sickle cell disease and thalassaemia in primary care: cluster randomised trial. BMJ 2010; 341: c5132.

4. Zeuner D, Ades AE, Karnon J, et al. Antenatal and neonatal haemoglobinopathy screening in the UK: review and economic analysis. Health Technol Assess 1999; 3(11): i-v, 1-186.

5. Department of Health. NHS reference costs 2005-2006. London: Department of Health, 2006

http://www.dh.gov.uk/en/Publicationsandstatistics/Publications/PublicationsPo licyAndGuidance/DH_062884 (accessed 13 Apr 2011).

6. Curtis L, Netten A. Unit costs of health and social care 2006. Canterbury: Personal Social Services Research Unit, University of Kent, 2006.

7. Curtis L. Unit costs of health and social care. Canterbury: Personal Social Services Research Unit, University of Kent, 2010.

8. Lunn DJ, Thomas A, Best N, Spiegelhalter D. WinBUGS - a Bayesian modelling framework: concepts, structure, and extensibility. Stat Comput 2000; 10: 325-337.

9. Doubilet $P$, Begg $C B$, Weinstein $M C$, et al. Probabilistic sensitivity analysis using Monte Carlo simulation: a practical approach. Med Decis Making 1985 5(2): 157-177.

10. Office for National Statistics. Census 2001. London: ONS, 2003.

11. Bellis MA, Hughes K, Hughes S, Ashton JR. Measuring paternal discrepancy and its public health consequences. J Epidemiol Community Health 2005; 59(9): 749-754.

12. Slattery MM, Morrison JJ. Preterm delivery. Lancet 2002; 360(9344): 1489-1497

13. Roberts TE, Robinson S, Barton PM, et al. The cost-effectiveness of home based population screening for Chlamydia trachomatis in the UK: economic evaluation of the Chlamydia Screening Studies (ClaSS) Project. BMJ 2007; 335(7614): 291-294

14. Bricker L, Garcia J, Henderson J, et al. Ultrasound and screening in pregnancy: a systematic review of the clinical effectiveness, cost-effectiveness and women's views. Health Technol Assess 2000; 4(16): i-vi, 1-193.

15. Karnon J, Goyder E, Tappenden P, et al. A review and critique of modelling in prioritising and designing screening programmes. Health Technol Assess 2007; 11(52): iii-iv, ix-xi, 1-145.

16. Cronin EK, Normand C, Henthorn JS, et al. Organisation and costeffectiveness of antenatal haemoglobinopathy screening and follow up in a community-based programme. Br J Obstet Gynaecol 2000; 107(4): 486-491.

17. Phelan L. An analysis of the relative costs and potential benefits of different policies for antenatal screening for B thalassaemia trait and variant haemoglobins. J Clin Pathol 1999; 52(9): 697-700.

18. Gallivan S, Jit M, Utley M, Lilford RJ. A stochastic model to evaluate options for antenatal genetic screening. CORU Working Paper - CORU Research Report 672. London: University College, 2003 